\title{
Management of central giant cell granuloma: A case series
}

\author{
Kavita Wadde $^{1 *}$, Jayant Landge ${ }^{2}$, Sandip Rathod ${ }^{3}$, Ashwini Chapane ${ }^{4}$ \\ ${ }^{1,2}$ Associate Professor, ${ }^{3,4} \mathrm{PG}$ Student, Dept. of Oral \& Maxillofacial Surgery, Government Dental College \& Hospital, Mumbai, \\ Maharashtra, India
}

*Corresponding Author: Kavita Wadde

Email: dr.kavitawadde@gmail.com

\begin{abstract}
Central giant cell granuloma (CGCG) is an uncommon, benign, and proliferative lesion of the jaw with an unknown aetiology, was first described by Jaffe in 1953. The lesion is found predominantly in children and young adults, with more than $60 \%$ of all cases occurring before the age of 30 years. The female: male ratio is 2:1. Lesions are more common in the anterior region of the jaws, and mandibular lesions frequently extend across the midline. CGCG can be difficult to diagnose from other lesion of oral cavity like Hyperparathyroid tumour, Ameloblastoma, Odontogenic myxoma, Haemangioma, Cherubism, Central odontogenic fibroma, Aneurysmal bone cyst, Traumatic bone cyst. Numerous treatment modalities given in literature from non-surgical to surgical. This paper intends to focus on diagnosis, clinical presentation and different management options of CGCG. So our aim was to evaluate the response of treatment of CGCG to intralesional injection.
\end{abstract}

Keywords: Central giant cell granuloma, Midline, Intralesional steroid, Phase I therapy, Phase II therapy.

\section{Introduction}

Central giant cell granuloma (CGCG) is a benign intraosseous lesion first described by Jaffe in 1953. Is a common benign lesion accounting for approximately $7 \%$ of all benign tumours of the jaws. It is defined by the world health organization as an intraosseous lesion consisting of cellular fibrous tissue that contains multiple foci of haemorrhage, aggregations of multinucleated giant cells, and occasionally trabeculae of woven bone. ${ }^{1}$ Jaffe considered it as a locally reparative reaction of bone which can be possibly due to either an inflammatory response, haemorrhage or local trauma. Females are affected more frequently than males. It occurs over a wide age range. ${ }^{2}$ The incidence of CGCG in the general population is estimated to be $0.0001 \%$. Giant cell granulomas may be encountered in patients ranging from 2 to 80 years of age, $60 \%$ of cases occurring before the age of $30 .^{3}$

Giant cell granuloma is often confused with giant cell tumour. However, a giant cell tumour can be distinguished based on fact that it occurs commonly between the ages of 25 and 40yrs, usually involving the long bones and is more aggressive in nature, with frequent recurrence after curettage. ${ }^{4} \mathrm{CGCG}$ is categorised in to the aggressive and nonaggressive type based on their clinical and radiographic characteristics. ${ }^{5}$ Most commonly lesions are located in the anterior region of mandible, anterior to the first molar frequently crossing the midline. CGCG reveals erratic clinical features which range from slow growing asymptomatic swelling to the aggressive lesion with pain, osseous destruction, cortical plates perforation, root resorption and recurrence. Facial asymmetry is the most common sign with swelling which is usually painless. ${ }^{6}$

Radiographically they appear as well defined unilocular or multilocular radiolucency that is well delineated. Aggressive lesion demonstrates ill defined borders with variable amounts of cortical destruction on radiographs. ${ }^{7}$ Wispy septations and undulating borders are some of the characteristics features of a central giant cell granuloma. ${ }^{8}$ It may confused with several other lesions of jaws such as hyperparathyroidism, neurofibromatosis type 1, Noonan syndrome, Cherubism. ${ }^{9}$ Treatment options for CGCG vary from case to case depending on the clinical features and behaviour of lesion. It range from intralesional steroid injection followed by curettage, surgical excision of the lesion. ${ }^{5}$ The purpose of this study was to highlight our experience for intralesional injection in central giant cell tumour.

\section{Case 1}

A 26-year-old male presented to our department, complaints of painless swelling in the anterior mandibular region since 1 year. Patient noted swelling with lower anterior region which was small in size and gradually increased to present size. Past medical and dental history was not significant. On extraoral examination a hard, smooth and non tender swelling was evident extending from right corner of the mouth till the chin region on right side [Fig. 1]. Intraoral examination revealed a vestibular swelling in the lower anterior region measuring approximately $5 \times 3 \mathrm{~cm}$ extending from distal aspect of 41 to mesial aspect of 46 with significant vestibular obliteration in relation to $42-45$ on buccal and lingual sides. The overlying mucosa was normal. There was no discharge buccally and lingually. Grade I mobility was present with 43 and 44 teeth. No lymphadenopathy were noted.

Orthopantomogram revealed a well defined multilocular radiolucent lesion extending from 42 to 45 present in the body region of mandible, thinning of inferior border of mandible, showing displacement of the roots of $42 \& 43$. Slight root resorption seen with $42 \& 43$ [Fig. 2]. CBCT of mandible was done, axial view showed multilocular radiolucent lesion with expansion and thinning of buccal cortical plate in the right anterior and body region. Perforations of cortical plates were visible on buccal aspect in right body region [Fig. 3]. Aspirational biopsy was negative. Differential diagnosis of ameloblastoma, 
dentigerous cyst, odontogenic keratocyst, Hyperparathyroidism and central giant cell granuloma were made. Routine investigations were carried out. Endocrine assessment was done to rule out hyperparathyroidism. Alkaline phosphatase, parathyroid hormone, serum calcium and phosphorous levels were within normal limit. Incisional biopsy was taken showing hypercellular connective tissue stroma showing numerous proliferating plump to spindle to ovoid shaped cells. Numerous multinucleated foreign body giant cells are seen approximately the endothelial lined vascular channels giant cell contained 8-12 nuclei. Overall features are suggestive of Central Giant Cell Granuloma.

Since the lesion was aggressive we had planned for intralesional steroid injection and explained him about the phase 1 therapy that is intralesional injection and the surgical intervention. Intralesional injection with steroid was started. The procedure of intralesional steroid injection consists of $1 \mathrm{ml}$ triamcinolone acetonide (Kenacort -A 40mg, BristolMyers-squibb pty Ltd), $1 \mathrm{ml}$ of $2 \%$ lidocaine without epinephrine were mixed, $2 \mathrm{ml}$ of solution per $2 \mathrm{~cm}$ of lesion was injected at one time. The intralesional injection was given in different areas of lesion once in a week for 2 month. Radiographically, the post-operative OPG showed sclerotic borders with no gross reduction in the size of lesion [Fig. 4]. Due to no regression in the lesion by intralesional steroid injection. Surgical resection with continuity defect followed by fixation with reconstruction plate was planned. Prior informed consent was taken regarding the surgical intervention planned and also alteration of it if needed during surgery. Patient was taken in operation theatre under general anaesthesia with nasoendotracheal intubation. Under all aseptic precautions, crevicular incision was made from 32 to 46 in buccal aspect, along with vertical releasing incision. Mucoperiosteal flap were raised and the tumour was exposed. After exposing the lesion, we found that the tumour had perforated both labial and lingual cortical plates. Extraction of 31 and 46 was done vertical osteotomy was planned through the sockets, the anterior cut was taken through socket of 31 using burs whereas posterior cut was made through the socket of 46. Separation of bony cuts were done with osteotome. Prior to this removal of specimen, the remaining segment is stabilized by temporary intermaxillary fixation, the reconstruction plate was contoured prior to the excision of bone. And reconstruction plate was immediately secured with the screws [Fig. 5]. Complete haemostasis was achieved and thorough irrigation was done with betadine solution. Flap were closed with 3-0 vicryl round body sutures. Patient was extubated and was kept under observation. Excised specimen was sent for histopathological studies and was diagnosed Central Giant Cell Granuloma. Intravenous antibiotics and analgesics were given for a week. We kept patient on ryles tube for 1 week. Patient was advised strict liquid diet. Follow up of the patient was taken at $1^{\text {st }}, 2^{\text {nd }}, 3^{\text {rd }}, 6^{\text {th }}$ months and yearly. The healing was satisfactory.

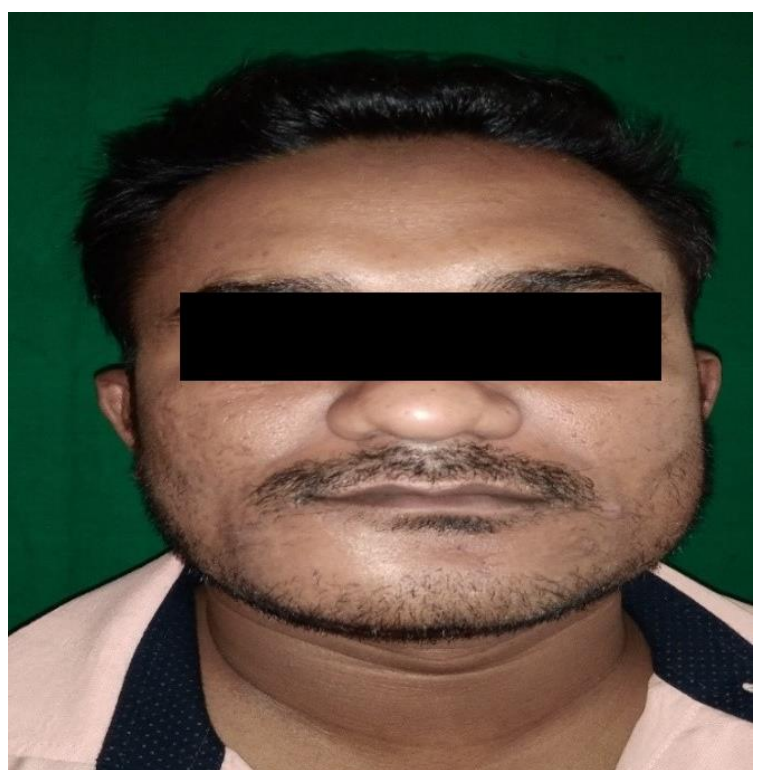

Fig. 1: Pre-operative extraoral profile view

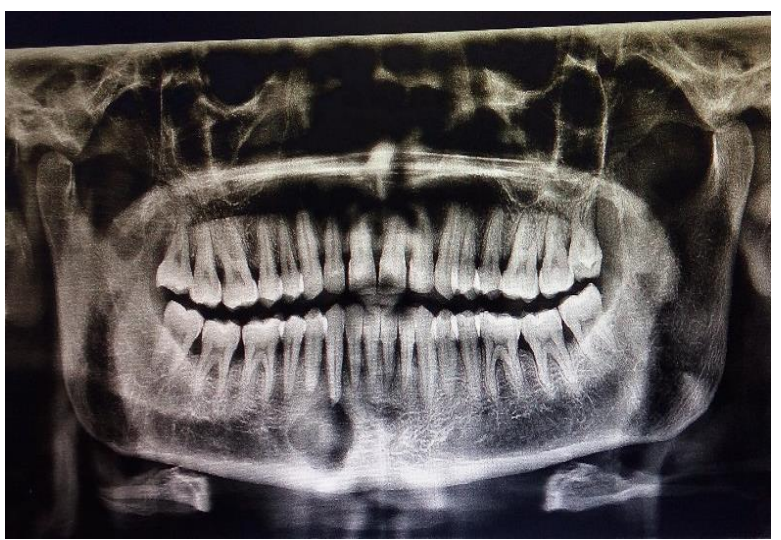

Fig. 2: Panoramic radiograph showing well defined multilocular radiolucent lesion extending from 42 to 45 in the right body region of mandible displacement of roots of 42 and 43

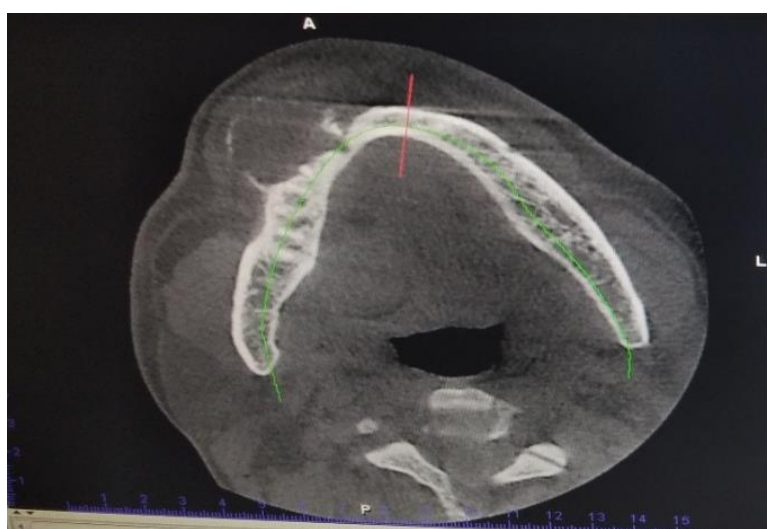

Fig. 3: CBCT scan: Axial view expansion and thinning of buccal cortical plate in the right anterior and body region 


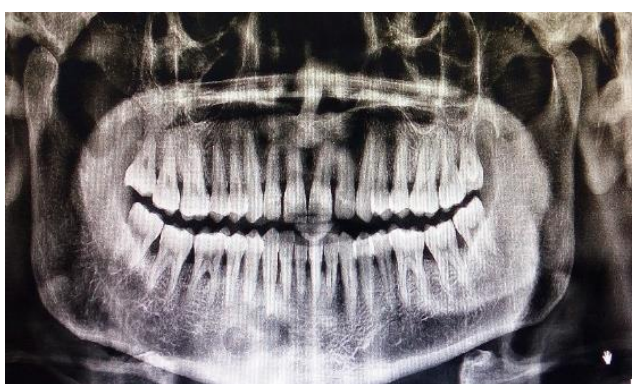

Fig. 4: Panoramic radiograph after 2 months of intralesional corticosteroid injection

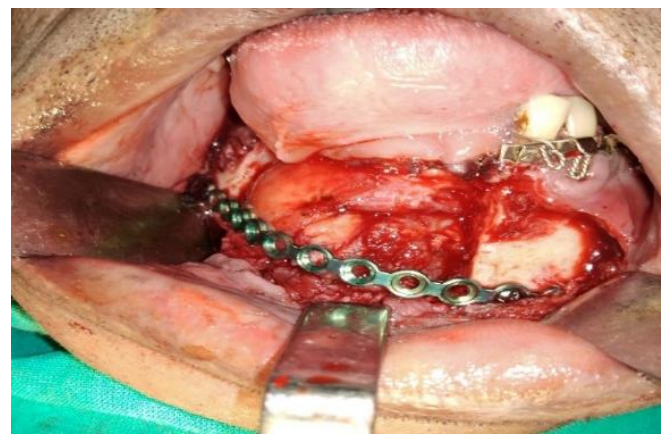

Fig. 5: Surgical resection with reconstruction plate

\section{Case 2}

A 26-year-old female reported to the department of orthodontics for the alignment of crowded teeth. For which orthopantomogram was taken coincidentally orthodontist noted an multilocular radiolucency in the lower left posterior region of mandible. So the patient was referred to department of oral and maxillofacial surgery. Patient was asymptomatic. No evidence of extraoral swelling and tenderness noted. Intraorally mild diffuse swelling was seen in the lower left posterior region. Overlying mucosa was normal. No draining sinus and no lymphadenopathy was present. Patient had a history of tuberculosis 7 years back, dental and family histories were non- contributory.

Orthopantomogram revealed well defined multilocular radiolucent lesion noted over the left angle of the mandible extending from mesial of 37 till the ramus. The lesion extends in to the interdental space between 37 and 38. External root resorption with 38 [Fig. 6]. CBCT of mandible was done, Axial view showed multilocular radiolucent lesion with expansion and thinning of lingual cortical plate in the left posterior region of mandible. Perforations of cortical plates were visible on lingual aspect in left posterior region of mandible. Aspirational biopsy was negative. Differential diagnosis made were Hyperparathyroidism, Unicystic Ameloblastoma, Dentigerous cyst, odontogenic keratocyst and CGCG were made. Routine investigations were carried out. Endocrine assessment was carried out to rule out hyperparathyroidism. Alkaline phosphatase, parathyroid hormone, serum calcium and phosphorus levels were within normal limit. Incisional biopsy was taken. Histopathological finding shows fibrocellular connective tissue stroma consisting of loose haphazardly arranged collagen fibres interspearsed of fibroblast. Numerous multinucleated giant cells of varying sizes also noted brown pigmented areas were noted. Diffuse mild chronic inflammatory cell infiltrated. Osseous tissue and haemorrhagic areas also seen. Overall features are suggestive of Central Giant Cell Granuloma. After overall considerations of patient age and morbidity after the surgical management of the lesion. The options of less invasive combined therapy were discussed with the patient. A phases of management protocol was initiated. In phase 1 intralesional steroid injection was given. The procedure of intralesional injection consists of $1 \mathrm{ml}$ triamcinolone acetonide (Kenacort -A 40mg, Bristol-Myers squibb pty Ltd), $1 \mathrm{ml}$ of $2 \%$ lidocaine without epinephrine were mixed, $2 \mathrm{ml}$ of solution per $2 \mathrm{~cm}$ of lesion was injected at one time, intralesional injection was given in the different areas of lesion once in a week for 2 months. After 2 months of steroid therapy. The post-operative OPG showed sclerotic borders with gradual increase in the opacity of radiolucent zone. New bone was formed but no gross reduction in the size of tumour [Fig. 7].

New bone formation was present by intralesional steroid injection. Due to no reduction in the size of tumour phase 2 therapy was carried out that is curettage with peripheral osteotomy. Prior informed consent was taken regarding the surgical intervention planned and also alteration of it if needed during surgery. Patient was taken in operation theatre under general anaesthesia with nasoendotracheal intubation. Under all aseptic precautions, crevicular incision was made from 34 to 38 on buccal aspect, along with vertical releasing incision. Mucoperiosteal flap were raised and the tumour was exposed. After exposing the lesion, we found that there is a perforation of lingual plate in lower left posterior region. Extractions were done with 36 and 37. Curettage with peripheral osteotomy was done [Fig. 8]. Inferior alveolar nerve was exposed and it was preserved.

Complete haemostasis was achieved and thorough irrigation was done with betadine solution. Flap were closed with 3-0 vicryl round body sutures. Patient was extubated and was kept under observation. Excised specimen was sent for histopathological studies and was diagnosed Central Giant Cell Granuloma. Intravenous antibiotics and analgesics were given for a week. We kept patient on ryles tube for 1 week. Patient was advised strict liquid diet. Follow up of the patient was taken at $1^{\text {st }}, 2^{\text {nd }}, 3^{\text {rd }}, 6^{\text {th }}$ months and yearly. The healing was satisfactory.

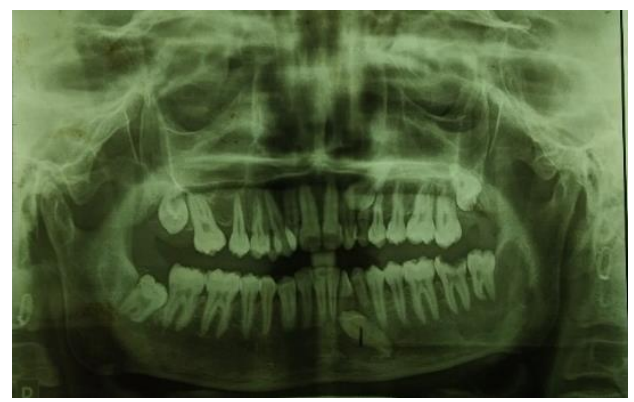

Fig. 6: Panoramic radiograph showing well defined multilocular radiolucent lesion over the left angle of mandible extending from mesial of 37 till the ramus 


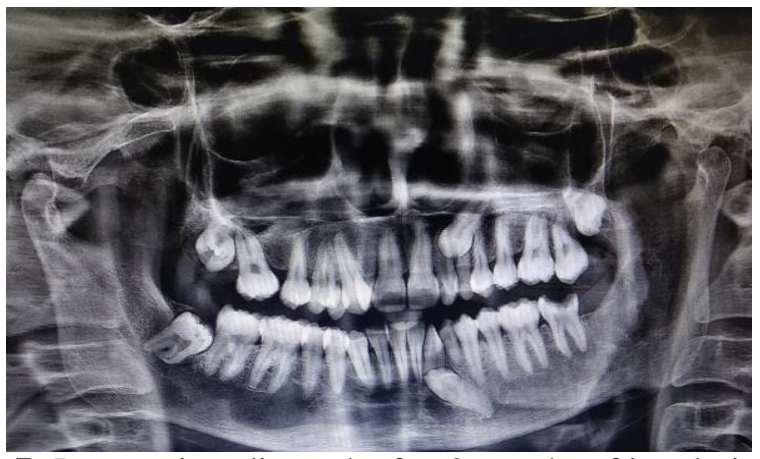

Fig.7: Panoramic radiograph after 2 months of intralesional corticosteroid injection showing sclerotic borders with gradual increase in the opacity of radiolucent zone

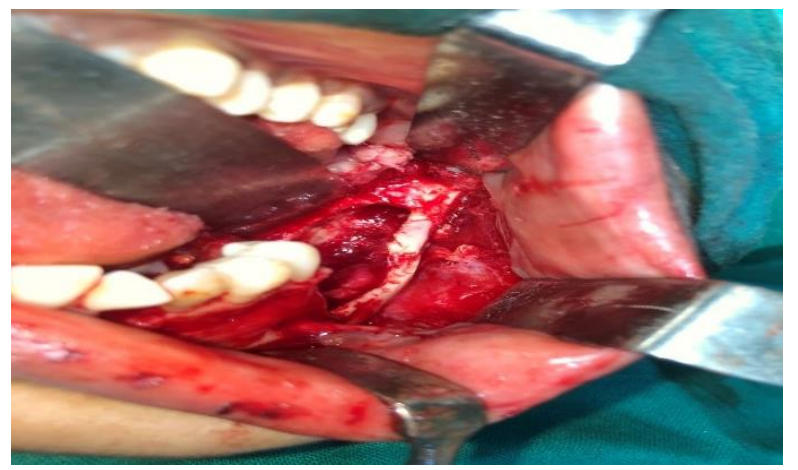

Fig. 8: Curettage with peripheral osteotomy

\section{Case 3}

A 30 year old male patient present with asymptomatic swelling present on the lower left posterior region of jaw. Orthopantomogram revealed well defined multilocular radiolucency in the body region extending from 33 to 36 [Fig. 9]. Routine blood investigations and endocrine assessment were carried out. It was within normal range. Incisional biopsy was taken and histopathological findings were suggestive of central giant cell granuloma. Same above surgical phases were carried out. In phase 1 intralesional injection was given. We found new bone formation along the margins and hence excision of the lesion was carried out [Fig. 10].

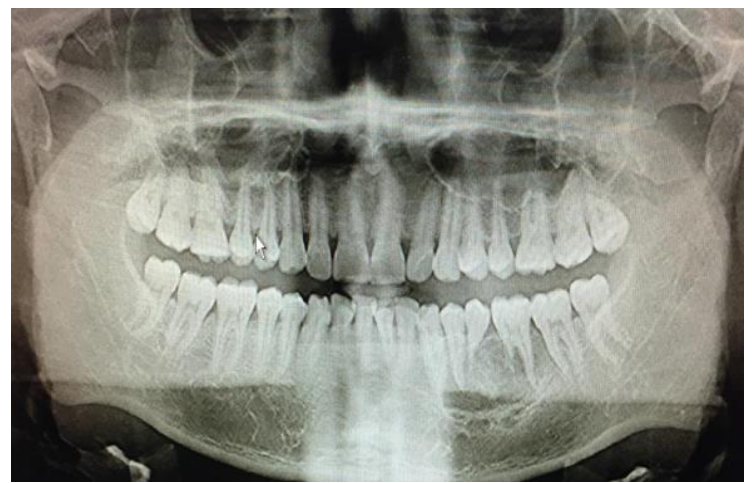

Fig. 9: Panoramic radiograph showing ill defined multilocular lesion extending from 33 to 36 in the left body region of mandible. External root resorption with 35 and 36

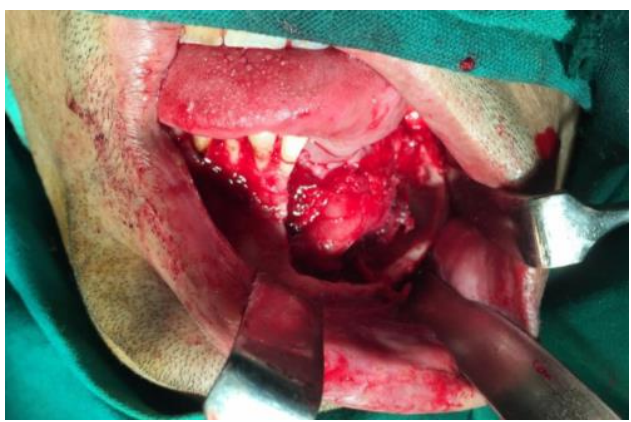

Fig. 10: Excision of lesion

\section{Discussion}

Central Giant Cell Granuloma of the jaws are most often found in children and young adults, with up to $75 \%$ cases occurring before 30 years of age. Females are affected twice as compared to males, most often occurs anterior to first molar teeth. The mandible is affected three times as compared to the maxilla, and the lesion may be seen to cross the midline. ${ }^{10}$ The lesion has been reported to be confined to the tooth bearing area of the jaw and is more common in anterior portion of the mandibular body. ${ }^{11}$

CGCG presents as a painless clinical expansion that may have a short ascendancy. The expanded lesion may appear blue because of its cortical and mucosal thinning and internal vascularity. Occasionally, the rapid expansion will stretch the periosteum, producing pain. ${ }^{10}$

The radiologic features of giant cell granuloma presents as a solitary radiolucency with multilocular or unilocular appearance. The borders may be well defined or ill defined and show variable expansion and destruction of the cortical plates. The internal structure may show granular pattern of calcification which is organised in to ill defined, wispy septa which emanates at right angels to the periphery of the lesion displacement and resorption of teeth are also evident. ${ }^{12}$

Grossly, these tumours are red to brown in colour with the mass consisting of a spindle cell stroma that may be quite cellular. There is variable amount of collagen, and mitosis are sometimes seen. Multinucleated giant cells are conspicuous and tend to be irregularly distributed throughout the mass, often concentrating in the areas of haemorrhage. It has been suggested that it may be a inflammatory lesion, a reactive lesion, a neoplasm, or an endocrine lesion. The proliferating cell in this lesion is fibroblast, which is believed to cytokines, resulting in recruitment of monocytes, which subsequently transform into multinucleated giant cells. ${ }^{7}$ With regard to the diagnosis, there were several pertinent differential diagnosis. The age and site were not consistent for a diagnosis of ameloblastoma, the absence of dental caries ruled out periapical and radicular cyst. Normal serum picture helped to rule out brown tumour (hyperparathyroidism), and cherubism due to its posterior presentation, size and radiographic appearance. $^{13}$

In 1986 CHOUNG et.al classified CGCG as aggressive or non aggressive according to six criteria. Selection of the best surgical procedure depends on many factors including biological behaviour (aggressive versus non aggressive), extent of the lesion, location, and radiological appearance. In 
aggressive CGCG, conservative surgical treatment by means of curettage enhanced by peripheral osteotomy is associated with recurrence of lesion. Bataineh et al suggested and En block resection with $5 \mathrm{~mm}$ healthy tissue safety margin as the treatment of choice to offer maximum confidence. ${ }^{5}$

Jacoway et al first reported administration of intralesional corticosteroid injection.is on of the essential non- surgical management methods for CGCG and has been associated with successful results. An additional study conducted by Terry and Jacoway in 1994 included four patients treated with steroids. A steroid injection administered to all patients every week for 6 weeks three of the four patient showed confirmed complete resolution of in $65 \%$ of cases. The remaining cases are either failed to respond to treatment or recurred aggressively. ${ }^{5}$

The procedure of intralesional steroids consists of $1 \mathrm{ml}$ triamcinolone acetonide (Kenacort -A 40mg, Bristol-Myers squibb pty Ltd), $1 \mathrm{ml}$ of $2 \%$ lidocaine without epinephrine were mixed and intralesional injection was given $2 \mathrm{ml}$ of solution per $2 \mathrm{~cm}$ of lesion was injected at one time. The intralesional injection was given in different areas of lesion once in a weeks for 2 months. Studies by Flanagan et al. indicted that multinucleated cells in giant cell granulomas of the jaws are osteoclasts and dexamethasone inhibition of osteoclast like cells in marrow culture support the use of intralesional corticosteroids for CGCG. Corticosteroids not only inhibit osteoclast activity but also result in rapid resolution including bone regeneration and recovery of normal functioning. The technique is simple, cost effective and relatively quick which avoids expressive aesthetic and functional defects. ${ }^{14}$ If giant cell granulomas appear as multiple lesions, surgical treatment becomes more difficult. Surgery may lead to extensive resection in such cases. JACOWAY et al. reported on an alternative approach using local corticosteroid injections. Because of the usually expansive growth of the CGCG, the thin bony cortex overlying the lesion may easily be perforated by a thin needle. ${ }^{15}$

In our cases, an attempt was made to check efficacy of intralesional corticosteroids for the patient based on non aggressive nature of this lesion. Phase- 1 management with corticosteroid in $1^{\text {st }}$ case was unsuccessful. After 2 months of corticosteroid therapy, there was no such marked regression in size of the lesion. In $2^{\text {nd }}$ case, follow up after intralesional injection was given. OPG showed gradual increase in the opacity of radiolucent zone. New bone was formed but no gross reduction in the size of tumour. Then we initiated Phase 2 surgical management. So we planned for surgical resection with continuity defect in case 1 . And curettage with peripheral osteotomy in case 2 . Similarly in $3^{\text {rd }}$ case excision of the lesion was done. We took follow up of the patient on $1^{\text {st }}, 2^{\text {nd }}, 3^{\text {rd }}, 6^{\text {th }}$ months and yearly postoperatively and there was satisfactory healing.

\section{Conclusion}

Management of aggressive CGCG can be done by different protocols. Intralesional corticosteroids was given preoperatively, was shown no gross reduction in the size of tumour however we have noted the radio-opacity and new bone formation in our $2^{\text {nd }}$ case which helps to remove the lesion more conservatively. Hence the intralesional injection does help in managing CGCG patients.

\section{Abbreviation}

CGCG- Central Giant Cell Granuloma.

\section{Source of Funding}

None.

\section{Conflict of Interest}

None.

\section{References}

1. Bataineh AB, Al-Khateeb T, Ma'amon AR. The surgical treatment of central giant cell granuloma of the mandible. $J$ Oral Maxillofac Surg. 2002;60(7):756-61.

2. Singh V, Malik S. Central giant cell granuloma of the mandible: A rare presentation. Int J Med Dent. 2012;16(2).

3. Iyengar AR, Shriyanka R, Vani MH, Simon SD. Central giant cell granuloma of posterior mandible: Report of a case. Int $J$ Med Dent Case Rep. 2016;3(1):1-5.

4. Mohan RP, Verma S, Agarwal N, Singh U. Central giant cell granuloma: a case report. BMJ Case Rep. 2013;22;2013:bcr2013009903.

5. Elhag HA, Babikir MH, Tarakji B. Advantages and disadvantages of surgical and non-surgical treatment of central giant-cell granuloma: A Review of literature. Int J Contemp Dent Med Rev. 2017;2017.

6. Singh G, Thakur A, Sadiq H, Gupta P. Central giant cell granuloma: A case report with diagnostic dilemma. Int $J$ Students' Res. 2015;5(1):11.

7. Raymond J. Fonseca. Oral \& Maxillofacial Surgery. $3^{\text {rd }}$ edition. Volume 2. p. 462.

8. Bayar OF, Ak G. Treatment of giant cell granuloma with intralesional corticosteroid injections: a case report. J Istanb Univ Fac Dent. 2015;49(3):45.

9. Abdelkarim AZ, el Sadat SM, Chmieliauskaite M, Syed AZ. Radiographic diagnosis of a central giant cell granuloma using advanced imaging: cone beam computed tomography. Cureus. 2018;10(6).

10. Marx, Robert E. Oral \& Maxillofacial Pathology: a rationale for diagnosis and treatment. $2^{\text {nd }}$ ed. Volume 2. P. 860-1.

11. Buduru K, Podduturi SR, Prakash J. Central giant cell granuloma: A case report and review. J Indian Acad Oral Med Radiol. 2017;;29(2):145.

12. Kamble KA, Guddad SS, Guddad SS, Lingappa A. Central giant cell granuloma: A case report with review of literature. $J$ Indian Acad Oral Med Radiol. 2016;28(1):98.

13. Balaji $\mathrm{P}$, Balaji SM. Central giant cell granuloma-A case report. Indian J Dent Res. 2019;30(1):130.

14. Al-Jandan B. Combined management of large aggressive central giant cell granuloma of the mandible: A case report. Saudi J Dent Res. 2015;6(2):157-60.

15. Kermer C, Millesi W, Watzke IM. Local injection of corticosteroids for central giant cell granuloma. A case report. Int J Oral Maxillofac Surg. 1994;23(6):366-8.

How to cite this article: Wadde $\mathrm{K}$, Landge J, Rathod S, Chapane A. Management of central giant cell granuloma: A case series. J Oral Med, Oral Surg, Oral Pathol, Oral Radiol 2020;6(1):36-40. 